\title{
Editorial
}

\section{Treatment of Children with Brain Tumors in Developing Countries*}

\author{
Michael A. Grotzer ${ }^{1}$ \\ ${ }^{1}$ Department of Paediatric Oncology, University Children's Hospital, \\ Zurich, Switzerland
}

Neuropediatrics 2012;43:231.

Unprecedented gains have been made in the cure rates for childhood cancer during the past five decades. This progress reflects steady improvements in treatment protocols, a multidisciplinary approach to patient care, adequate hospital infrastructure, and psychosocial and economic support for affected families. ${ }^{1}$ However, more than $80 \%$ of children live in low-income countries, where children with cancer have no or little access to effective therapy. ${ }^{2}$

Only limited data on incidence, therapeutic approaches, and survival for children with brain tumors in developing countries are available. ${ }^{2-6}$ Many cases are undiagnosed, and access to treatment is restricted by the availability of adequate health structures, although most countries with limited resources have neurosurgical facilities, radiation equipment and pediatric oncology units with experience in delivering chemotherapy. ${ }^{2}$

In the article by Rafsanjani et al that accompanies this editorial, outcome of 82 pediatric brain tumor patients treated in Ali-Asghar Children's Hospital, Teheran, Iran, is reported. ${ }^{7}$ Such scientific reports on treatment and outcome of childhood brain tumors in developing countries are the basis for discussing country-specific opportunities for improvement.

All institutions involved in childhood cancer worldwide need to have access to the latest progress through meetings, networking, and continuing professional development (included in the goals of the International Society of Pediatric Oncology and the International Society of Pediatric NeuroOncology). Access to the possibility of scientific reporting is similarly important.

Another strategy for improvement is described in the book Cancer in Developing Countries: The Great Challenge for Oncology in the 21st Century. ${ }^{8}$ It emphasizes a partnership (twinning) between institutions in developed countries and those

\footnotetext{
${ }^{*}$ This article is an editorial on "Outcome of primary childhood central nervous system tumors: results from a single center in Iran" by Rafsanjani et al (Neuropediatrics 2012;43(5):232-237).
}

Address for correspondence Prof. Dr. Michael A. Grotzer, MD, University Children's Hospital, Steinwiesstrasse 75, CH-8032

Zurich, Switzerland (e-mail:

Michael.Grotzer@kispi.uzh.ch). in developing countries. Especially in pediatric neurooncology, where a complex multidisciplinary approach is required together with quality control measures through centralized review of histology, imaging, radiotherapy planning, etc., such twinning programs might be of tremendous benefit, as recently demonstrated by Qaddoumi et al. ${ }^{2}$

Could it be that the article by Rafsanjani et al triggers interest and efforts to establish such a twinning program?

\section{References}

1 Ribeiro RC, Pui CH. Saving the children-improving childhood cancer treatment in developing countries. N Engl J Med 2005; 352(21):2158-2160

2 Qaddoumi I, Musharbash A, Elayyan M, et al. Closing the survival gap: implementation of medulloblastoma protocols in a lowincome country through a twinning program. Int J Cancer 2008; 122(6):1203-1206

3 Kadri H, Mawla AA, Murad L. Incidence of childhood brain tumors in Syria (1993-2002). Pediatr Neurosurg 2005;41(4):173-177

4 Karkouri M, Zafad S, Khattab M, et al. Epidemiologic profile of pediatric brain tumors in Morocco. Childs Nerv Syst 2010;26 (8):1021-1027

5 Akyüz C, Varan A, Küpeli S, et al. Medulloblastoma in children: a 32-year experience from a single institution. J Neurooncol 2008; 90(1):99-103

6 Mbonda E, Slaka CL, Djientscheu V, et al. Aspects cliniques, scanographiques et histologiques des tumeurs cérébrales de l'enfant à Yaoundé, Cameroun. Schw Arch Neurol Psych 2011;162(7): 284-287

7 Rafsanjani A, Bahoush G, Nikpoor F, Vossough P. Outcome of primary childhood central nervous system tumors: results from a single center in Iran. Neuropediatrics 2012;43(5):232-237

8 Tanneberger S, Cavalli F, Pannuti F, eds. Cancer in Developing Countries: The Great Challenge for Oncology in the 21st Century. Munich, Germany: Zuckschwerdt;2004
Copyright $\odot 2012$ by Thieme Medical Publishers, Inc., 333 Seventh Avenue, New York, NY 10001, USA. Tel: +1(212) 584-4662.
DOI http://dx.doi.org/ 10.1055/s-0032-1327469. ISSN $0174-304 \mathrm{X}$. 